AL-QAnTtara

XXXVIII 1, enero-junio 2017

pp. $45-70$

ISSN 0211-3589

doi: $10.3989 /$ alqantara.2017.002

\title{
La versión árabe del De divinatione per somnum de Aristóteles y su impacto en Avicena y su teoría de la profecía
}

\author{
The Arabic Version of Aristotle's De divinatione \\ per somnum and Its Impact in Avicenna's \\ Theory of Prophecy
}

\author{
Luis Xavier López-Farjeat \\ Universidad Panamericana, Ciudad de México \\ orcid.org/0000-0003-1140-2913
}

The Epistle concerning Dreams (Risāla alManāmiyya) is a little known work where Avicenna deals with some relevant considerations regarding the way in which prophecy and veridical dreams take place. The theory contained in this- treatise accurately illustrates how intricate Avicenna's theory of prophecy is and, at the same time, provides several clues in order to recognize the origin of this theory as it appears in major treatises such as fi al-Nafs and Ilāhiyāt of the Šifă'. The Risāla al-Manāmiyya also enables us to recognize the impact of several influences coming from the Ancient Greek tradition-mainly from Aristotle, Galen, Plotinus, and other Neoplatonics. This article explains the theories of divination by means of dreams and the conception of prophecy, as they appear in the Arabic version of the De divinatione per somnum, a treatise where the origins of Avicenna's theory of prophecy can be found. Furthermore it shows the impact that the theory contained in this treatise had in the Risāla al-Manāmiyya. Finally, it expounds some remarks regarding the transmission and adaptation of the metaphysical
La Epístola sobre los sueños (Risāla al-Manāmiyya) es un breve tratado donde Avicena se ocupa de algunas consideraciones relevantes acerca del modo en que se suscitan la profecía y la adivinación a través de los sueños. La teoría que aparece en dicho tratado ilustra con precisión cuán intrincada es la teoría de la profecía de Avicena y, al mismo tiempo, aporta varias pistas para reconocer el origen de dicha teoría tal como aparece en tratados mayores como fì al-Nafs e Ilāhiyāt de la Šifā'. La Risāla al-Manāmiyya también nos permite reconocer el impacto de varias influencias provenientes de la tradición griega, principalmente de Aristóteles, Galeno, Plotino, y otros Neoplatónicos. Este artículo explica las teorías de la adivinación a través de los sueños y de la profecía tal como aparecen en la versión árabe del De divinatione per somnun, un tratado donde pueden encontrarse los orígenes de la teoría de la profecía de Avicena. Además, muestra el impacto que la teoría contenida en este trabajo tuvo en la Risāla al-Manāmiyya. Finalmente, expone algunas consideraciones concernientes a la transmisión y adaptación de 
and psychological points of view posed both in the Arabic version of the De divinatione and the Risāla al-Manāmiyya, alluding to the impact they had in the theories of prophecy found both in Avicenna's major treatises in the Sifiā'.

Key words: Avicenna, prophecy, divination by dreams. los planteamientos metafísicos que aparecen tanto en el De divinatione como en la Risāla al-Manāmiyya, aludiendo al impacto que ambas obras tuvieron en las teorías de la profecía que encontramos en los tratados mayores de Avicena.

Palabras clave: Avicena, profecía, adivinación a través de los sueños.

\section{Introducción}

En los Parva Naturalia, un grupo de escritos breves redactados muy probablemente después del De anima, Aristóteles discute acerca de una serie de experiencias sensitivas comunes tanto al alma como al cuerpo. Entre esos breves tratados se encuentra uno intitulado De divinatione per somnum, donde Aristóteles rechaza categóricamente que los sueños puedan tener un origen divino (463b12-22). Sin embargo, en la versión árabe que circulaba muy probablemente desde el siglo IX, aparece una postura distinta. Los árabes conocieron los Parva Naturalia bajo el título general de Kitāb al-Hiss wa-al-maḩsūs que en realidad es el título del primer tratado, el De Sensu et Sensibilibus. Rotraud Elisabeth Hansberger, ${ }^{1}$ quien ha revisado minuciosamente el manuscrito árabe - una copia de 1752 hallada por Hans Daiber en 1985, en Rampur - ha hecho notar que no se trata de una traducción sino de una adaptación impregnada de ideas neoplatónicas y galénicas que se separa notoriamente del texto original de Aristóteles. ${ }^{2}$

Hansberger ha retomado una línea temática que si bien había sido discutida previamente desde finales del siglo XIX por M. Steinschneider, ${ }^{3} \mathrm{y}$

${ }^{1}$ La tesis doctoral de Hansberger, The Transmission of Aristotle's Parva Naturalia in Arabic, trata precisamente sobre la transmisión de los Parva Naturalia en el contexto árabe, además de presentar la primera edición crítica del único manuscrito existente. Desafortunadamente hasta el momento su trabajo no ha visto la luz. Parte de su investigación ha sido publicada, sin embargo, en artículos en los que además presenta, traduce y comenta algunos pasajes relevantes. Véase Hansberger, "How Aristotle Came to Believe in Godgiven Dreams: The Arabic Version of De divinatione per somnum", pp. 50-77; "Kitāb alHiss wa-l-mahsūs: Aristotle's Parva Naturalia in Arabic Guise", pp. 143-162; "Plotinus Arabus Rides Again", pp. 57-84; "The Arabic Adaptation of the Parva Naturalia (Kitāb al-Hiss wa-l-mahsūs)", pp. 301-314.

${ }^{2}$ Véase Hansberger, "Kitāb al-Hiss wa-l-mahsūs: Aristotle's Parva Naturalia in Arabic Guise", p. 143. Véase también Daiber, "Salient Trends of the Arabic Aristotle", pp. 29-41.

${ }^{3}$ Véase Steinschneider, "Die Parva Naturalia des Aristoteles bei den Arabern", pp. 477-492; pp. 447-453. 
por S. Pines en los años setenta del siglo XX, ${ }^{4}$ no ha sido lo suficientemente explorada a pesar de la cantidad de aspectos que merecen analizarse y discutirse. Mi intención aquí es indagar en el impacto que la versión árabe del De divinatione habría tenido en la filosofía de Avicena y, en consecuencia, contribuir a la detección de una serie de planteamientos provenientes de Aristóteles, Galeno, Plotino y posiblemente Proclo, readaptados en la tradición filosófica islámica con la finalidad de justificar un fenómeno esencial en la tradición islámica y común a las tres tradiciones abrahámicas, a saber, la profecía. ${ }^{5}$ Pines ya había sugerido que la Risāla al-Manāmiyya, un tratado de Avicena poco estudiado, podía considerarse una fuente esencial para detectar una versión del De divinatione per somnum que no parecía ser la de Aristóteles. ${ }^{6}$ Mis intenciones son distintas: pretendo mostrar el impacto que tuvo ese tratado aristotélico en la filosofía de Avicena, sobre todo en su teoría de la profecía.

No se ha publicado todavía una edición crítica del manuscrito árabe de los Parva Naturalia. ${ }^{7}$ Si acaso la falta de dicha edición crítica y el hecho de que el manuscrito de Rampur esté incompleto, ha contribuido a que los contenidos filosóficos de dicho tratado reciban escasa atención. De acuerdo con los aportes de Hansberger, el manuscrito está divido en tres secciones (maqālas). En la primera aparece el De Sensu; la segunda está dividida en dos partes: la primera es una versión del De memoria et reminiscentia y, la segunda, incluye el De somno et vigilia, el De insomniis y el De divinatione per somnun, todos reunidos bajo un mismo título, al-Nawm wa-al-yaqaza (De somno et vigilia); en la tercera sección se encuentra el De longitudine et brevitate vitae. ${ }^{8}$ En

${ }^{4}$ Véase Pines, "The Arabic Recension of Parva Naturalia and The Philosophical Doctrine Concerning Veridical Dreams According to al-Risāla al-Manāmiyya and Other Sources", pp. 104-153.

${ }^{5}$ En un trabajo previo he analizado la teoría de la profecía de Avicena y el modo en que Tomás de Aquino la interpreta en De veritate q. 12, a. 3. En aquél trabajo se enfatiza en el contraste que hay entre una especie de comprensión natural de la profecía (Avicena) y una concepción sobrenatural (Tomás de Aquino). Véase López-Farjeat, "Avicenna and Thomas Aquinas on Natural Prophecy", pp. 309-333.

${ }^{6}$ Véase Pines, "The Arabic Recension", pp. 152-153.

${ }^{7}$ Al finalizar la redacción de este artículo recibo noticias de que Hansberger está por concluir dicha edición, un trabajo que, sin duda, será una gran aportación a los estudios sobre la filosofía árabe-islámica.

${ }^{8}$ Véase Hansberger, Kitāb al-Hiss wa-l-maḥsūs: Aristotle's Parva Naturalia in Arabic Guise", p. 143. 
los folios 40r a 47v se habla de la veracidad de los sueños y es precisamente ahí donde se sostiene tanto el origen divino de los sueños como la posibilidad de adivinar o predecir a través de éstos. ${ }^{9}$ Aunque evidentemente el texto nada tiene que ver con el original, lo llamativo es que el adaptador formula una explicación novedosa sobre el carácter divino y adivinatorio de los sueños que, como he mencionado, se nutre de otras fuentes médicas y filosóficas, y resulta en una tesis coherente que inspiraría tanto a filósofos como a teólogos islámicos y judíos, que no dudaron en atribuir a Aristóteles una doctrina acerca del origen divino de los sueños útil para justificar la profecía.

En lo que sigue explicaré las teorías de la adivinación a través de los sueños y de la profecía natural que aparecen en la versión árabe del De divinatione per somnum. ${ }^{10}$ Posteriormente hablaré del impacto de esta teoría en un breve y poco conocido tratado de Avicena donde se ocupa directamente de la adivinación a través de los sueños y la profecía, a saber, la Risāla al-Manāmiyya. Finalmente, haré algunas observaciones sobre la transmisión y adaptación de los planteamientos metafísicos y psicológicos que se encuentran tanto en la versión árabe del De divinatione como en la Risāla, aludiendo al impacto que tuvieron en las teorías de la profecía que aparecen tanto en fi al-Nafs como en Ilāhiyāt de la obra monumental de Avicena, el Kitāb al-Šifă 'o Libro de la Sanación. Concluiré mostrando cómo la concepción de la profecía que sostiene Avicena, se nutre considerablemente de la versión árabe del De divinatione y, en consecuencia, de variedad de fuentes griegas.

\section{Los orígenes de la teoría de la profecía de Avicena}

Como he adelantado, en la versión griega original del De divinatione per somnun, Aristóteles rechaza la postura según la cual Dios envía sueños verídicos y, en cambio, sostiene que este fenómeno puede ser explicado sin necesidad de recurrir a un origen divino. En este sentido provee tres posibles causas de la adivinación a través de los sueños:

\footnotetext{
${ }^{9}$ Véase Hansberger, "How Aristotle Came to Believe in God-given Dreams", p. 52.

${ }^{10}$ Puesto que no está publicada la edición crítica del De divinatione, los pasajes analizados y discutidos provienen de los trabajos que Hansberger ha publicado. Véase la nota número 1.
} 
(1) podría tratarse de la continuación de un proceso ya iniciado en el cuerpo humano durante la vigilia, y que continúa por distintos motivos, sobre todo biológicos, durante el sueño; ${ }^{11}(2)$ o bien podría deberse a que alguien tiene un sueño y posteriormente de manera inconsciente hace que dicha situación ocurra; ${ }^{12}$ y finalmente (3) podría ser que, por mera coincidencia, suceda en realidad lo que alguien soñóo. ${ }^{13}$ En contraste, la versión árabe de este tratado aborda esta cuestión explicándola desde dos consideraciones complementarias: (1) que la causa de los sueños verídicos es Dios (si bien, como veremos, esto no implica una intervención sobrenatural), y (2) que el alma humana requiere de ciertas facultades — "facultades espirituales" (al-quwā al-rūḥ̂̄niyya) — para poder recibir los sueños verídicos. ${ }^{14}$

La primera cuestión, es decir, Dios como causa de los sueños verídicos, se presenta bajo un marco metafísico neoplatónico: Dios es la causa primera o suprema que crea todos los seres existentes, mismos que antes de llegar a ser en forma material en el mundo existen en forma intelectual en un primer intelecto, llamado 'intelecto universal' (al-'aql al-kulli). Dicho intelecto emana de Dios y contiene todo lo que Él ha creado. Esta postura, que afirma que Dios crea a través de un intelecto universal, concuerda con las nociones neoplatónicas de "causalidad primera" y "causalidad segunda". ${ }^{15}$ Aunque Dios sea la causa fundamental de todo evento en el mundo, la causa directa no es Él sino el intelecto universal. La presencia de esta distinción, a mi juicio, sugiere que el adaptador del De divinatione habría sido influido por Plotino y posiblemente también por Proclo. La distinción entre causalidad primera y segunda es central en el llamado Kalām fì maḥ al aljayr o Discurso sobre el bien puro, conocido en la tradición latina como el Liber de causis, y que no es sino un conjunto de pasajes, paráfrasis y

${ }^{11}$ Aristóteles, De Divinatione 463a3-21.

${ }^{12}$ Aristóteles, De Divinatione 463a21-23.

${ }^{13}$ Aristóteles, De Divinatione 463a31b11.

${ }^{14}$ Véase Hansberger, "How Aristotle Came to Believe in God-given Dreams", p. 56; Di Martino, "La Perception Spirituelle. Perspectives de Recherche pour l'Historie des Parva Naturalia dans la Tradition Arabo-Latine", pp. 21-35.

${ }^{15}$ Véase D'Ancona, "La notion de «cause» dans les textes Néoplatoniciens Arabes", pp. 47-68; D' Ancona, L'influence du vocabulaire arabe: "Causa Prima est esse tantum", pp. 51-97; D'Ancona, “"Causa prima superior est omni narratione». Il tema delle sifat Allah nel primo neoplatonismo arabo", pp. 519-555; Taylor, "Primary Causality and $i b d \bar{a}^{\text {c }}$ (creare) in the Liber de causis", pp. 115-136; Taylor, "Primary and Secondary Causality", pp. 225-235. 


\section{readaptaciones de los Elementos de Teología de Proclo y de las Enéa-} das de Plotino. ${ }^{16}$

Lo que estas tres obras tienen en común es que refieren a la importancia de una causa primera generadora de una causa segunda que, a su vez, es capaz de generar una serie de efectos o consecuencias que, aunque provienen remotamente de la causa primera, dependen finalmente de ésta en tanto que es una causa superior. En otros términos, la causa primera actúa a través de causas segundas o intermedias, pero no por ello pierde su agencia causal. Este mismo proceso tiene lugar en el caso de los sueños verídicos: Dios o la primera causa es su causa definitiva, pero el intelecto universal es su transmisor o causa próxima. Esto significa que Dios no actúa directamente en lo que crea, ni decide tampoco enviar sueños verídicos a seres humanos particulares en un momento dado:

El verdadero Dios, exaltado sea, es la causa y razón de la verdadera visión a través de los sueños, [y esto lo lleva a cabo] a través de la mediación del intelecto,

\footnotetext{
${ }^{16}$ Algunos pasajes tanto de las Enéadas como de los Elementos de Teología y del Liber de causis son ilustrativos para la comprensión de las nociones de "causalidad primera" y "causalidad segunda": "Si se da algo a continuación del Primero, es necesario que o provenga inmediatamente de aquél o se remonte hasta aquél a través de los intermediarios, y que exista un orden de Segundos y Terceros en que uno - el Segundo- se remonte al Primero y el Tercero al Segundo. Ha de darse, en efecto, algo anterior a todas las cosas que sea simple y esto debe ser distinto de todos los posteriores a él, que subsista en sí mismo y que no esté mezclado con los provenientes de él (...)" (Enéadas V.4, 1-10). "Es por tanto evidente que el efecto es determinado en mayor medida por el principio superior. Pues, si el segundo ha conferido al ser secundario la causalidad que le permitió producir, entonces él mismo debe poseer primeramente dicha causalidad (proposición 18), y es gracias a esto que el ser secundario genera, habiendo derivado de su antecesor la capacidad de la generación secundaria. Pero si el secundario produce por participación, y el primario lo hace primeramente y por comunicación, entonces el segundo es causante en mayor medida, en tanto que ha comunicado a otro el poder de generar consecuentes (Proclo, Elementos de Teología, prop. 56)". "Toda causa primera emana más abundantemente en su efecto de lo que lo hace la causa segunda universal. Y cuando la causa segunda universal retira su poder de la cosa, la causa primera universal no retira su poder de ésta. Pues la causa primera universal actúa en el efecto de la causa segunda universal que está inmediatamente adyacente a [el efecto] y actúa sobre [el efecto]. Así, cuando la causa segunda que está inmediatamente adyacente a los efectos actúa, su acto no es capaz de efectuarse sin la causa primera que está por encima [de la causa segunda]. Y cuando la [causa] segunda se separa del efecto que está inmediatamente adyacente a ésta, la causa primera que está por encima [de la causa segunda] no se separa a sí misma [del efecto], porque es la causa de la causa [del efecto]. Por lo tanto, la causa primera es en mayor medida la causa de la cosa que la causa próxima de la misma, y que está inmediatamente adyacente a [la cosa] (Liber de Causis, prop. 1).
} 
pues todo lo que Dios, exaltado sea, quiso que se manifestara en este mundo, Él lo representó en el intelecto de un modo inmediato, y representó sus formas en este mundo de manera inmediata, junto con sus implicaciones lógicas. El intelecto luego las hizo manifiestas al alma y a cada una de sus facultades, en la medida en que el alma decidiera que la facultad pudiera recibirlas, dado que la Causa Suprema, es decir, Dios, exaltado sea, las creó de esta manera, cuando creó el intelecto en aquel momento, para hacer manifiesto lo que hay en él; porque Dios movió [al Intelecto] para hacer manifiesto lo que hay en él. ${ }^{17}$

El intelecto universal juega una suerte de papel mediador y es quien distribuye los sueños verídicos. Los individuos que gozan de capacidades psicológicas especiales son capaces de recibirlos e interpretarlos. Ésta es la razón por la que quien adaptó el tratado de Aristóteles complementa la explicación metafísica con una postura psicológica, a saber, con la exposición de las así llamadas facultades espirituales. Al parecer, la explicación del adaptador de este tratado sobre las facultades espirituales se basa en la concepción galénica de tres facultades mentales localizadas en el cerebro, a saber, la imaginación productiva o formativa ( nazr o zann) y la memoria ( $\mu v \eta \dot{\mu \eta} /$ al-dikr). ${ }^{18}$ Estas tres facultades permanecen activas incluso durante el sueño, y funcionan como receptáculo tanto de nuestros sueños ordinarios como de los verídicos. Durante nuestros sueños ordinarios, estas tres facultades operan sobre imágenes retenidas previamente en la mente, sobre todo, en la cogitativa; sin embargo, en los sueños verídicos las imágenes no son provistas por experiencias sensitivas previas, sino por el intelecto universal. Es por ello que el adaptador de la versión árabe del De divinatione aclara que las imágenes a las que accedemos a través de los sueños podrían tener algún significado ( $m a$ ' $n \bar{a}$ ) o podrían ser completamente huecas o vacías:

(...) cuando [alguien] está inmerso en el sueño hace que el significado ( $m a$ ' $n \bar{a}$ ) esté presente junto con la forma. Así, el que duerme ve las formas de las cosas y recibe la interpretación de éstas a través de dicho significado ( $m a$ ' $n \bar{a})$ que [ya] ha estado en [la facultad del] pensamiento (al-fikr / cogitativa). Posteriormente la persona que está teniendo la visión en el sueño creerá que esa visión en el sueño es verídica y que lo que está viendo es una realidad; sin embargo, es algo completa-

\footnotetext{
${ }^{17}$ al-Nawm wa-al-yaqaza, f. 42r. Citado por Hansberger, "The Arabic Adaptation”, p. 307.

${ }^{18}$ Véase Hansberger, "Kitāb al-Hiss wa-l-maḥsūs: Aristotle's Parva Naturalia", pp. $145-146$.
} 
mente hueco, y no tiene ningún significado $(m a$ ' $n \bar{a})$. Esto ocurre gracias a estas facultades espirituales, es decir, a la [facultad] formativa [o imaginativa], la cogitativa y la memoria- ya que ni el movimiento, ni la actividad de estas facultades entran en reposo durante el sueño. Pues cuando la naturaleza reposa y es absorbida en el alma, entonces el cuerpo descansa; y cuando el cuerpo descansa los sentidos también están en reposo, y cuando los sentidos están en reposo, el sentido común recurre a la [facultad] formativa [o imaginativa], y ve con una mirada espiritual las formas de las cosas que ha visto en el dominio de la corporalidad. [Antes] las veía cuando eran corpóreas y estaban en movimiento, mientras que [ahora] las ve estando en reposo e inmóviles en la [facultad] formativa, siendo más perfectas y excelentes en reposo que estando en movimiento. ${ }^{19}$

Las tres facultades recién mencionadas también son tratadas por Aristóteles en distintos lugares del De anima y también en De Memoria et Reminiscentia. Podría pensarse, por lo tanto, que el adaptador podría haber estado influido igualmente por Aristóteles. Creo, sin embargo, que hay razones para decantarse por una influencia galénica. En efecto, en Sobre las doctrinas de Hipócrates y Platón (De Placitis Hippocratis et Platonis) Galeno habla específicamente de estas tres facultades sin las cuales no habría cognición, y la misma presentación de las facultades aparece en la versión árabe de los epitomes alejandrinos de Galeno. ${ }^{20}$

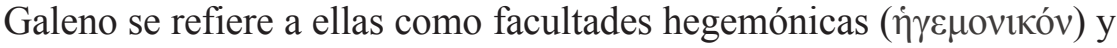

19 al-Nawm wa-al-yaqaza, f. 40v 1-26. Citado por Hansberger, "How Aristotle Came to Believe in God-given Dreams", p. 60.

20 "Hay tres funciones directivas: la imaginación, la cogitativa y la memoria. Cada una de las tres posee una excelencia deseable y un defecto indeseable. Por lo tanto, la excelencia de la imaginación radica en aceptar rápidamente el conocimiento. Éste es uno de los indicadores de que la parte anterior del cerebro y recibe imágenes rápidamente, ya que la imaginación se encuentra en esta región particular del cerebro. El temperamento mejor dispuesto para esto es el temperamento moderadamente húmedo, dado que es imposible que algo que está seco y duro adopte imágenes y pueda así recibir fácilmente la forma, y esto tampoco puede ocurrir con algo que esté demasiado húmedo. El punto medio entre estos dos extremos es el mejor. El defecto de la imaginación -su estado defectuoso- es la dificultad para ser instruida. Ésta es una de las cosas que indican que la parte anterior del cerebro es dura y que si recibe impresiones y recibe formas sólo lo hace con dificultad. Esta dureza es consecuencia de una de dos cosas, a saber, sequedad o frío. En este contexto es más probable que esté asociado con la sequedad. La excelencia y perfección del pensamiento se manifiesta en una sutileza mental y en una rapidez de ingenio. Éstas se cuentan entre las cosas que evidencian la sutileza del espíritu psíquico. La sutileza del espíritu psíquico dependerá de la consecución de una mezcla completa. La consecución de la mezcla completa será resultado de un calor moderado y una cantidad limitada de humedad. El defecto del pensamiento -su estado defectuoso- es el retraso y la lentitud en la comprensión. Éstas indican una tosquedad del espíritu psíquico. La tosquedad del espíritu psíquico ocurre por una de dos cosas: ya sea por humedad o frío excesivos. La excelencia de la memoria 
ubica cada una de ellas, si no en un sitio específico del cerebro, sí actuando en distintos ventrículos cerebrales: la imaginación en el ventrículo frontal del cerebro, la cogitativa en el ventrículo medio, y la memoria en el ventrículo posterior. Llama la atención, principalmente, la descripción de la cogitativa, ya que Galeno le asigna la función de manipular imágenes. De este modo, mientras que la imaginación se encarga de integrar los estímulos sensoriales externos (actividad que en la psicología aristotélica lleva a cabo el sentido común), y la memoria almacena las imágenes provistas por la imaginación y la cogitativa, la cogitativa tiene un papel, podría decirse, más operativo al manipular las imágenes. Naturalmente una actividad de este tipo puede vincularse de inmediato con los sueños, entre ellos los verídicos, constituidos precisamente por la combinación de distintas imágenes.

Además de la forma en que operan estas tres facultades mentales, ha de hacerse notar el modo en que el adaptador se refiere a ellas: "facultades espirituales" (al-quwā al-rūhāniyya). Galeno concibió que el pneuma vital ( $\pi v \varepsilon \tilde{u} \mu \alpha \zeta \omega \tau \imath \kappa o v /$ spiritus vitalis) era responsable de la asimilación de los nutrientes transportados a través de la sangre y que aquél, al llegar al cerebro a través de las arterias, se transformaba en

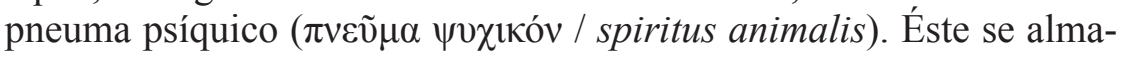
cenaba entonces precisamente en los ventrículos cerebrales activando de este modo a las tres facultades mentales. Hay cierta ambigüedad en la manera como Galeno concibe la interacción entre el pneuma psíquico y los ventrículos cerebrales: podría pensarse que los ventrículos cerebrales conforman el soporte físico de las facultades mentales; sin embargo, éstas no podrían operar sin la presencia de esa materia sutil denominada pneuma psíquico. ${ }^{21} \mathrm{Al}$ margen de las distintas interpretaciones que puedan suscitarse y que de hecho se suscitaron alrededor de este problema, lo cierto es que el adaptador de la versión árabe del De divinatione asimiló que estas facultades eran espirituales, es decir, que no operaban de manera exclusivamente orgánica

se observa en la facilidad para recolectar, lo que indica que la parte posterior del cerebro está seca. Ahí es donde se localiza la memoria, y la memoria necesita de algo que tenga estabilidad y permanencia, atributos propios de una cosa seca. El defecto de la memoria -su estado defectuoso- es el olvido, lo que indica que la porción posterior del cerebro está más húmeda de lo que debiera. Algo que está húmedo corre y fluye, sin tener por tanto ni quietud ni permanencia" (Versión árabe de los Epitomes alejandrinos de Galeno, prop. 33).

${ }^{21}$ Para esta discusión véase por ejemplo C. U. M. Smith, "Beginnings of Ventricular Psychology", pp. 2-19. 
El tratamiento dado a las facultades espirituales en la versión árabe del De divinatione per somnun merece especial atención: en el contexto de nuestros procesos intelectivos comunes, el papel de estas facultades, también conocidas posteriormente como "sentidos internos" 22 - junto con el sentido común (al-hiss al-muštarak) y, en el caso de Avicena, la imaginación retentiva (al-jayāl) y la facultad estimativa (wahm) - es auxiliar al momento de aprehender la forma intelectual (șüra 'aqliyya) de un objeto; no obstante, como apunta Hansberger, en la versión árabe del De divinatione per somnun, estas facultades también acceden en algunos casos - esto es, en los sueños verídicos - a lo que en este tratado se denomina la "forma espiritual" (șüra rūhāniyya). Esta capacidad es tratada cuando el adaptador discute por qué en ocasiones los sueños verídicos no retratan los eventos futuros con precisión si provienen del intelecto universal. El adaptador explica que algunas veces lo que se percibe en los sueños verídicos es la forma espiritual, mas no la forma corporal (șüra jismāniyya): por ejemplo, se podría soñar algo que está ocurriendo en una ciudad específica, mientras que este lugar en el sueño no se asemejara a dicha ciudad particular. ${ }^{23}$

La forma espiritual sólo es similar a la forma corpórea y es una imagen de la forma intelectual. Es importante esta concepción de la "forma espiritual" puesto que se trata, en esencia, de una imagen no construida a partir de datos provistos por la sensación externa, pero que de hecho se asemeja a una forma corporal; por otra parte, al ser la forma espiritual constitutivamente una imagen, no puede ser sino un símil de la forma intelectual. Lo que se observa en este planteamiento es un intento por otorgar un papel cognitivo a las imágenes oníricas tal como se producen en los sueños verídicos, es decir, sin provenir de las experiencias sensitivas ni tampoco del proceso intelectivo habitual. A pesar de no provenir de estímulos sensitivos, estas imágenes se reciben en las tres mismas facultades mentales y el sentido común. En otras palabras, en

\footnotetext{
${ }^{22}$ Para una revisión exhaustiva en torno a la función de los sentidos internos, véase Wolfson, "The Internal Senses in Latin, Arabic, and Hebrew Philosophic Texts", pp. 69133; Black, "Estimation in Avicenna: The Logical and Psychological Dimensions", pp. 219258; Black, "Imagination and Estimation: Arabic Paradigms and Western Transformations", pp. 59-75; di Martino, "Memory and Recollection in Ibn Sīnā's and Ibn Rushd's Philosophical Texts Translated into Latin in the Twelfth and Thirteenth Centuries: A Perspective on the Doctrine of the Internal Senses in Arabic Psychological Science", pp. 17-25.

${ }^{23}$ Véase Hansberger, "How Aristotle Came to Believe in God-given Dreams...", p. 57.
} 
el caso de los sueños verídicos, según la versión árabe del De divinatione, los humanos son capaces de acceder a los inteligibles sin la mediación de los sentidos externos, pues en ese caso el intelecto activo universal provee los inteligibles directamente a las facultades internas, en primer lugar al sentido común que, a su vez, transmite estos contenidos a la imaginación productiva:

[...] la verdadera visión espiritual durante el sueño se da a partir de los inteligibles [provistos por el] intelecto universal, y no [a partir] de los inteligibles del intelecto adquirido, [pues aquéllos] son desconocidos para el sentido común y [no han sido] imaginados por la facultad formativa [o imaginación]; [sus] significados [son además] desconocidos para la [al-fikr/cogitativa], y [tampoco] son depositados en la facultad de la memoria. Cuando estas formas aparecen en la visión durante el sueño, y cuando el sentido común, la facultad formativa [o imaginativa] y el resto de las facultades las observan, sabrán entonces que las formas provenientes de ellas a partir de los objetos corporales de percepción son algo vano. ${ }^{24}$

El adaptador del De divinatione no solamente explica el proceso de recepción de los sueños verídicos sino que también se refiere a su interpretación. Para comprender el significado de los sueños verídicos el receptor del sueño necesita alcanzar un estado de pureza del alma y del cuerpo que le permita desarrollar la habilidad para interpretar esos símbolos. Lo llamativo en este caso es que en la interpretación de los sueños se requiere del mismo proceso. En otras palabras, no es la facultad intelectiva humana la que interpreta los sueños sino que, de nueva cuenta, es el intelecto universal el que permitiría ya sea al intérprete o a quien tuvo la visión descifrar el sentido de los sueños y expresarlos a través de "palabras espirituales" (kalimāt rūḥāniyya), es decir, símbolos y metáforas.$^{25}$ Esto quiere decir que el proceso cognitivo que jus-

${ }^{24}$ al-Nawm wa-al-yaqaza, f. 41r 5-11. Citado por Hansberger, "The Arabic Adaptation", p. 307.

25 "Si la cogitativa no puede [encontrar] un significado, en ese momento la persona [que ha soñado] expondrá su caso a un intérprete. Algunas veces el intelecto fluye sobre el intérprete con [dichas] palabras espirituales, y su lengua las pronunciará, mientras percibe que él es quien está interpretando [correctamente] la visión en el sueño. En otras ocasiones el Intelecto no fluirá sobre el intérprete, y éste cometerá errores y no sabrá qué decir o qué debería interpretar. El intelecto puede fluir sobre el intérprete por una de dos razones: o bien porque el intérprete es espiritual, y por tanto el Intelecto fluirá sobre él dada su espiritualidad, o bien, fluirá sobre él por signos que se manifiesten en el mundo. (al-Nawm wa-al-yaqaza, f. 42v - 43r). Citado por Hansberger, "How Aristotle Came to Believe in God-given Dreams", p. 59. 
tificaría los sueños verídicos se explica exclusivamente por la interacción del intelecto universal y las facultades internas que operan con imágenes. El siguiente pasaje expresa lo anterior:

La evidencia que viene a confirmar lo que hemos dicho es la visión en el sueño del Rey Heracles en la que vio aquellas columnas. [Él soñó] que vio aquellas columnas milagrosas mientras estaba despierto; además de ver éstas también vio aquellas palabras espirituales; así que siguió maravillándose de ellas durante mucho tiempo. Luego hizo venir a varios intérpretes para que explicaran su visión en el sueño, pero ninguno de ellos pudo hacerlo correctamente, pues le daban una explicación contraria a la verdad. Pero cuando el rey volvió a dormir pudo ver las palabras espirituales que correspondían a la interpretación de su visión en el sueño, y vio las formas de lo que iba a ocurrir en el mundo a partir de las formas espirituales que había visto antes. Por lo tanto, cuando despertó de su sueño ya no tuvo necesidad de recurrir a los intérpretes, y aceptó como verdadera la explicación de la interpretación que le fue dada en su sueño y rechazó la falsa versión de sus intérpretes. Mantuvo [...] aquella visión en el sueño, hasta que lo que había visto en sueños ocurrió en el mundo. La interpretación de la visión del sueño que recibió mientras dormía era verdadera y correcta, mientras que la de los intérpretes era incorrecta. $^{26}$

Algunos elementos de esta teoría sobre la adivinación a través de los sueños se encuentran en varios pensadores árabes y judíos, especialmente cuando tratan una cuestión, como he mencionado, de especial relevancia entre las tradiciones abrahámicas, a saber, la profecía. La versión árabe del De divinatione fue una fuente importante para la configuración de diversas doctrinas en torno a la profecía: aunque Alfarabi no se refiere de manera explícita a este tratado sobre la adivinación, la presencia de ideas similares en su obra La ciudad ideal (al-Madīna al-fădila) es notoria. ${ }^{27}$ Avicena y Avempace refieren explícitamente al tratado, el primero, como se ha dicho, en la Risāla al-Manāmiyya, y el segundo en El régimen del solitario (Kitāb Tadbīr al-mutawaḥhid). ${ }^{28}$ En su Epitome a los Parva Naturalia (Talkhīs Kitāb al-Hiss wa-al-mahsūs), muy conocido en el medievo latino dese el siglo XIII, Averroes presenta la misma doctrina que aparece en la ver-

${ }^{26}$ al-Nawm wa-al-yaqaza, f. 41v 16 a 42r 2. Citado por Hansberger, "How Aristotle Came to Believe in God-given Dreams", p. 63.

${ }^{27}$ Véase al-Fārābī, On the Perfect State (Mabādi' ārā' ahl-al-Madīna al-Fädila), pp. 218-227.

${ }^{28}$ Véase Avempace, El Régimen del Solitario, p. 116. 
sión árabe del tratado de Aristóteles. ${ }^{29}$ En cuanto a la tradición judía, Maimónides y otros desarrollaron una teoría similar. ${ }^{30}$

\section{Sobre la adivinación en la Risāla al-Manāmiyya de Avicena}

La Risāla al-Manāmiyya es una obra poco conocida en donde hay consideraciones relevantes sobre el modo en que se presenta el fenómeno de los sueños verídicos y la profecía. La teoría que aparece en este tratado ilustra acertadamente cuán intricada es la teoría de la profecía en Avicena, tal como aparece en tratados mayores como fi al-Nafs e Ilāhiyāt, pero también nos permite reconocer el impacto de distintos puntos de vista provenientes de la tradición antigua - neoplatónica, aristotélica y galénica.

En su estudio sobre la influencia del De anima de Avicena en el Occidente latino, Dag Hasse ha hecho notar cómo en dicho tratado, el $f i$ al-Nafs de Avicena, se describen tres diferentes tipos (niveles o condiciones) de profecía: ${ }^{31}$ (a) el primero es explicado como un acto donde la facultad imaginativa es tan poderosa que algunas personas tienen visiones incluso cuando están despiertas, y esto ocurre porque existe una conexión entre las almas de las esferas celestes y la facultad imaginativa (ésta es la teoría que aparece tanto en la Risāla, en fi al-Nafs, e incluso en Ilāhiyatt); ${ }^{32}$ (b) el segundo se relaciona con las facultades motoras (movimiento y decisión), y es descrito como la capacidad del alma para ejercer poder sobre la materia al grado de transformarla (por ejemplo, el poder de sanar o hacer enfermar a otros, o de transformar una materia en otra), ${ }^{33}$ (c) el tercer tipo se relaciona con el intelecto, y consiste en la obtención de inteligibles a través de una intuición (hads), lo que explica por qué algunas personas son capaces de adquirir el término medio de un silogismo sin ningún esfuerzo (esta explicación se

${ }^{29}$ Véase Averroes, Epitome a los Parva Naturalia, pp. 66-92.

${ }^{30}$ Véase Maimónides, Guía de los perplejos II, 32, pp. 327-330.

${ }^{31}$ Hasse, Avicenna's De anima in the Latin West, pp. 154-155.

${ }^{32}$ Si bien hay cierta discusión sobre si el autor de la Epístola sobre los sueños es Avicena, este texto coincide en gran parte con la doctrina desarrollada en otras obras suyas. Por lo tanto, considero que la discusión sobre su autoría puede dejarse de lado. Para más discusión a este respecto, así como argumentos que apoyan la autoría de Avicena, véase Pines, "The Arabic Recension of Parva Naturalia", pp. 104; 123.

${ }^{33}$ Véase Avicena, Šifă': al-Nafs 5.2, p. 178. 
asemeja a la versión que encontramos en otro tratado titulado Sobre la prueba de las profecías (Fi ithbāt al-nubuwwāt), y aparece igualmente en fi al-Nafs y en Ilāhiyāt). ${ }^{34}$ Aquí pondré particular atención en el primer tipo de profecía puesto que es el que aparece en la Risāla y cuyo impacto en fì al-Nafs y en Ilāhiyāt intentaré mostrar.

En la Risāla encontramos una descripción muy similar a la que aparece en el De divinatione, es decir, en términos de una conexión entre la imaginación y el intelecto activo. En la Risāla se discuten primeramente una serie de problemas que aparecen en el De somniis de Aristóteles, el tratado que precede al De divinatione en los Parva naturalia. Dichas cuestiones son tratadas desde una postura más biológica (qué es el sueño, por qué los animales duermen y qué tipo de cosas vemos durante el sueño), pero luego se exploran algunas otras cuestiones psicobiológicas y metafísicas (qué facultades son requeridas para experimentar las visiones en el sueño y cuál es su causa eficiente). Finalmente, Avicena trata los diversos tipos de visiones en el sueño y es aquí en donde aborda la profecía como tal.

La explicación psicológica es uno de los puntos en los que guarda mayor similitud con la versión árabe del De divinatione, pero también con la psicología de fi al-Nafs. Como destaca Pines, la imaginación (mutajayyila) ocupa un lugar privilegiado dentro de la Risāla, y Avicena enfatiza su capacidad para reproducir las formas de las cosas percibidas por los sentidos externos, para evocar imágenes del pasado, y para componer nuevas imágenes; también explica que mientras los animales humanos están despiertos, su imaginación es supervisada por la facultad cogitativa (fikriyya), si bien mientras duermen opera por sí misma y combina imágenes de forma peculiar. ${ }^{35} \mathrm{~A}$ diferencia del $\mathrm{De}$ divinatione en donde el adaptador se refiere a un grupo de facultades que operan con imágenes, Avicena se concentra específicamente en la imaginación (mutajayyila). Después de presentar las funciones de dicha facultad, explica que hay ocasiones en las que un intelecto universal provee los contenidos imaginativos.

Avicena se refiere también a tres modos en los que la imaginación

${ }^{34}$ Véase Avicena, Šifă': al-Nafs 4.4, p. 200.

${ }^{35}$ Véase Pines, "The Arabic Recension of Parva Naturalia", p. 109. Para una explicación detallada sobre las capacidades de la imaginacion, véanse principalmente los capítulos segundo, cuarto y quinto del texto árabe de Avicena, Risāla al-Manāmiyya, pp. 278-279; pp. 282-285. 
actúa durante el sueño: (1) en algunos casos la imaginación retiene las formas provistas por los sentidos externos antes de dormir; (2) en algunos casos transfiere las formas que ya estaban actuando sobre la facultad cogitativa (como en el caso de alguien que sueña algo que ocurrió durante el día); y finalmente (3), cuando en ocasiones los sueños son resultado de una alteración del temperamento (por ejemplo, cuando se sueña con objetos ligeros y luminosos cuando el temperamento es cálido, o lluvia y agua cuando es húmedo). ${ }^{36}$ De estos tres casos, tanto (1) como (2) se ajustan a una de las posibilidades contempladas por Aristóteles para explicar los sueños, a saber, la continuación mientras dormimos de un estímulo sensorial o de imágenes previamente retenidas. El caso (3), por su parte, responde a un fenómeno de orden biológico: los temperamentos influyen en la producción de imágenes durante el sueño. Pero éstos no son los únicos tipos de visiones en el sueño. En el sexto capítulo Avicena afirma que hay otros casos en los que la causa eficiente de estas visiones no es la sensación, la cogitativa o el temperamento, sino un poder divino (hadhihi'l-quwā al-ilāhiyya). ${ }^{37}$

Para que este tipo de visión pueda ocurrir dos cosas son necesarias: una causa, esto es, Dios, y una facultad que exista fuera de los seres humanos. Pueden notarse las similitudes con la versión árabe del De divinatione, en donde igualmente se apela a una causa primera y a un intelecto intermedio para justificar los sueños verídicos. En el noveno capítulo de la Risāla esa facultad o intelecto intermedio recibe el nombre de "intelecto activo" (al 'aql al-fa " $\bar{a} l$ ) o "intelecto universal" (al'aql al-kullī), y Avicena menciona que esto es precisamente lo que sostiene Aristóteles en De sensu et sensato (Kitāb al-Hiss wa-almahsūs), el título con el que los Parva Naturalia fueron conocidos entre los árabes. ${ }^{38}$ En el octavo capítulo se explica cómo es que Dios actúa a través de una fuerza divina que es descrita como penetrando todo el mundo. ${ }^{39}$ Avicena afirma que esta fuerza ha recibido diferentes

\footnotetext{
${ }^{36}$ Véase Avicena, Risāla al-Manāmiyya, pp. 283-285; para la versión en inglés véase la traducción del propio M. A. Mu'id Khan en "Kitāb ta 'bīr al-ru'ya of Abu 'Ali b. Sina”, pp. 28-30; para su traducción y comentario véase Pines, "The Arabic Recension of Parva Naturalia", pp. 110-113. El nexo entre los sueños y los temperamentos puede encontrarse también en al-Fārābī, On the Perfect State (Mabādi' ārā' 'ahl-al-Madīna al-Fādila), pp. 215-217.

${ }^{37}$ Véase Avicena, Risāla al-Manāmiyya, pp. 286-288; para la versión en inglés véase "Kitāb ta"bīr al-ru'ya", pp. 43-30.

${ }^{38}$ Véase Avicena, Risāla al-Manāmiyya, p. 294; para la versión en inglés véase "Kitāb ta 'bīr al-ru'ya", p. 48.
} 
denominaciones entre distintos grupos y sectas; por ejemplo, esto es lo que los sabios griegos llamaban emanación divina (al-fayd al-ilāh $\bar{\imath}$ ) o divina providencia (al-'ināya al-ilāhiyya).$^{40}$ Éstas son las dos denominaciones que mejor describen el mecanismo por el que son recibidas las visiones en el sueño.

Antes de explicar cómo esta providencia o fuerza divina transmite las visiones en el sueño, Avicena advierte que actúa especialmente en hombres superiores y que éstos son de dos clases, a saber, reyes justos o filósofos excelentes, los primeros con notables habilidades prácticas y los segundos con grandes habilidades teóricas. Por tanto, han de considerarse dos condiciones: el poder de Dios para actuar a través de una emanación y, tal como sucede en la versión árabe del De divinatione, algunas disposiciones humanas. El siguiente es un pasaje clave donde las visiones del sueño se identifican con la profecía (entendida como la recepción de conocimiento sobre eventos futuros), y donde este fenómeno se explica como una emanación divina mediada por el intelecto activo o universal:

Cuando habla sobre las visiones durante el sueño en el libro titulado De sensu et sensato, Aristóteles atribuye esta fuerza al intelecto activo ( $a l$ - 'aql al-fa " $\bar{a} l$ ).

Dice [Aristóteles]: la verdadera visión espiritual en el sueño [consiste en] una representación (tașawwur) del intelecto universal (al- 'aql al-kullī) que contacta a un intelecto particular durante el sueño. Esto [significa] que cuando Dios, sea exaltado, decreta (qaddara) algo a un hombre, él [podría] informar y advertir a éste a través de la mediación del intelecto universal, mostrándole a su alma durante el curso del sueño una forma o una imagen que indica lo que le ocurrirá a dicho hombre en el futuro. Estas [indicaciones corresponden] a una de dos especies. Pueden ser especiales, indicando el estado particular del hombre [en cuestión], o generales, indicando lo que ocurrirá a la humanidad como un todo, [como ocurrió] en el caso de la visión en el sueño del Rey Heracles. [Éste] tuvo un sueño y mandó llamar a los intérpretes, quienes le informaron lo que habían descubierto en su visión en el sueño e interpretaron sus hallazgos relativos a éste. Cuando Heracles durmió por

${ }^{39}$ Véase Avicena, Risāla al-Manāmiyya, pp. 290-291; para la versión en inglés véase "Kitāb ta 'bīr al-ru'ya", p. 46. Esta descripción es muy cercana a la de Alejandro de Afrodisias en el Mabādi'. Es bien sabido que Alejandro fue una fuente relevante para Avicena, por lo que encontramos ecos de él en su cosmología y, en este caso, se trata de otra ruta de interpretación. Para una exploración sobre la doctrina de la "fuerza divina penetrando todo el mundo", véase la introducción a Alexander of Aphrodisias, On the Cosmos, pp. 1-5; véanse también en esta misma edición los parágrafos 127-136, pp. 113-115.

${ }^{40}$ Véase Risāla al-Manāmiyya, pp. 291-292; para la versión en inglés véase "Kitāb ta 'bīr al-ru'ya", p. 47; para una traducción al inglés con comentario véase Pines, "The Arabic Recension of Parva Naturalia", pp. 115-117. 
segunda vez, vio a la misma persona que le había mostrado su visión en el sueño y [esta persona] le dijo: "La interpretación [correcta] de tu visión en el sueño no es lo que ellos piensan, sino que es [la siguiente]". De esta manera Heracles llegó a la interpretación [correcta] de su [visión en el sueño]. [Entonces] Heracles viajó alrededor del mundo y estableció reinos en las montañas, los desiertos y los mares, zonas [geográficas] bien delimitadas, trazó caminos y vías y diferenció entre [diversas] clases de personas. A partir de esto es claro que la verdadera causa de las visiones verídicas en el sueño es Dios, exaltado sea, y que Él informa a los hombres a través de la mediación del intelecto universal sobre lo que ocurrirá en el futuro al hombre particular y a toda la humanidad. Este intelecto universal es, por así decirlo, un intermediario entre Dios, sea exaltado, y el alma particular del hombre; [y] Dios, sea exaltado, ha creado en [el intelecto universal] de una vez por todas las formas (de las cosas) que han ocurrido. Por tanto [las entidades] que se encuentran bajo [el intelecto universal] pasan a [las entidades] bajo éstas de acuerdo a un orden [fijo] de [estas formas] hasta llegar al hombre. E indica también la utilidad de estas visiones en el sueño. Ésta es la opinión del filósofo respecto a la fuerza en cuestión. ${ }^{41}$

Este pasaje describe la caracterización de las visiones del sueño o sueños verídicos como aquellos en los que Dios provee representaciones particulares a cierto intelecto a través de la intervención del intelecto universal. Lo que este tratado tiene en común con la versión árabe del De divinatione es la apelación a una primera causa que, a través de un intelecto universal, provee contenidos cognitivos que en algunos casos pueden ser recibidos por las facultades mentales que permanecen activas durante el sueño. Todo indica que en la Risāla Avicena integra una serie de elementos provenientes de la cosmología neoplatónica con aspectos provenientes de la psicología galénica y aristotélica. En la siguiente sección subrayaré la presencia de estos aspectos en fi al-Nafs y en Ilähiyāt, dos tratados mayores que forman parte de su principal obra El libro de la sanación (Kitāb al-Šifā').

\section{La profecía en fĩ al-Nafs y en Ilāhiyāt de la Šifă,}

La explicación psicológica de la profecía aparece en fi al-Nafs 4.2, donde Avicena se refiere a la profecía de la facultad imaginativa. ${ }^{42}$ Ex-

${ }^{41}$ Véase Avicena, Risāla al-Manāmiyya, pp. 294-295; para las versiones en inglés véase "Kitāb ta "bīr al-ru'ya", pp. 48-49 y para una traducción al inglés con comentario véase Pines, "The Arabic Recension of Parva Naturalia", pp. 120ss.

${ }^{42}$ Avicena, Šifă': al-Nafs 4.2, p. 173. 
plica que algunas personas poseen una imaginación tan poderosa e inusual que actúa independientemente de los sentidos, y que incluso en algunos casos su imaginación opera directamente bajo la influencia de las almas de las esferas celestes ${ }^{43}$ que, como se explicará, son responsables de todo evento (pasado, presente y futuro) en el mundo sublunar. ${ }^{44} \mathrm{La}$ facultad imaginativa, según Avicena, transforma en imágenes los contenidos procesados por el sentido común y retenidos en la memoria. Dado que para Avicena la facultad imaginativa no se reduce a un receptáculo pasivo, sino que se trata de una facultad activa, posee la capacidad de evocar, combinar y separar su conjunto de imágenes dotándolas de un significado coherente. Esto último es a lo que él llama ahí "profecía".

La explicación de fi al-Nafs 4.2. corresponde a la "profecía imaginativa", la misma que aparece en la Risāla. Sin embargo, en fì al-Nafs 5.6, cuando Avicena expone los grados de intelección, introduce lo que él denomina la "profecía intelectual". ${ }^{45}$ Precisamente en el contexto en

${ }^{43}$ Avicena, Šifă': al-Nafs 4.2, p. 178.

${ }^{44}$ En cuanto a la influencia de las esferas celestes en el mundo sublunar, véase Gutas, "Imagination and Transcendental Knowledge in Avicenna", pp. 337-354.

${ }^{45}$ Previamente en al-Nafs 5.1, Avicena explica que los seres humanos tienen una facultad inmaterial, a saber, el intelecto teórico ('aql nazararî), mismo que les permite abstraer o aprehender las formas inmateriales a partir de las cosas materiales, y es precisamente esto lo que él llama "intelección”. En otras palabras, Avicena se refiere a la intelección como la capacidad del alma para aprehender la forma a partir de la materia, adoptándola para sí (Šifä': al-Nafs 5.6, p. 239). La forma es aprehendida a partir de la materia a través de un proceso por el cual el intelecto elimina cualquier traza de materialidad o propiedades particulares como serían el color, la forma, el tamaño, etc.; no obstante, también se dan otros casos en los que las formas ya están separadas en sí mismas y por tanto el intelecto sólo las recibe. Avicena afirma que hay diferentes grados de abstracción o de aprehensión $\mathrm{y}$, de acuerdo con éstos, el intelecto teórico recibe diferentes nombres. El intelecto material ('aql hayūlānì) se encuentra en nosotros al modo de un receptáculo potencial de las formas (Šifä': al-Nafs 1.5, pp. 48-49). Cuando el intelecto logra captar los inteligibles primarios (ma 'qūlāt ūlá) o primeros principios, como "el todo es mayor que la parte", se le llama entonces 'intelecto disposicional' ('aql bi-l-malaka). No es claro, sin embargo, si estos primeros inteligibles emergen espontáneamente a través del intelecto material, o bien, si son una especie de principios a priori provistos por el intelecto agente. Para una discusión a este respecto, véase Gutas, Avicenna and the Aristotelian Tradition: Introduction to Reading Avicenna's Philosophical Works, pp. 192-204; Davidson, Alfarabi, Avicenna, and Averroes, on Intellect, pp. 85-87; Hasse, Avicenna's De anima in the Latin West, pp. 179-180). Ahora bien, cuando los primero inteligibles ya están presentes en intelecto disposicional y se captan los inteligibles secundarios (a saber, los contenidos del mundo externo), éste recibe entonces el nombre de 'intelecto actual' ('aql bi-l-fi $l$ ). La explicación que provee Avicena en el al-Nafs acerca de la función de este intelecto resulta insuficiente, ya que 
el que provee una compleja explicación del proceso de intelección, es decir, del modo en que el intelecto humano puede abstraer o aprehender las formas inmateriales de los objetos materiales, Avicena sostiene que la actualización de las formas inteligibles requiere de la intervención de un intelecto separado (la décima esfera en su modelo cosmológico), es decir, el intelecto activo o intelecto agente ( $a$ l' $a q l$ al-fa " $\bar{a} l) .{ }^{46}$ Evidentemente la concepción por demás compleja del intelecto agente en Avicena no proviene exclusivamente de Aristóteles sino de una larga tradición de comentadores de la antigüedad tardía. Lo que importa para efectos de la presente discusión es que en fi al-Nafs 5.5 Avicena explica que el intelecto activo o intelecto agente actúa al modo de un mediador que permite que ocurra el proceso de abstracción del intelecto humano a través de la iluminación de los objetos de abstracción..$^{47}$ El contacto entre este intelecto superior y el intelecto humano o particular en sus tres formas (material, disposicional y actual) para que pueda tener lugar la intelección (es decir, en la etapa que Avicena llama "intelecto adquirido") es llamado "conjunción" (ittișāl) ${ }^{48}$ Las formas inteligibles son aprehendidas sólo cuando esta conjunción ocurre. Avicena explica, sin embargo, que las formas inteligibles no permanecen en la mente humana o intelecto porque, dada su constitución material (el cerebro y las facultades localizadas en éste), ${ }^{49}$ no hay lugar para almacenarlas.

Aunque los inteligibles no están en la mente, el alma racional es capaz de adquirirlos en todo momento que los requiera. El alma racional humana puede desarrollar el hábito o capacidad para aprender, i.e. de unirse con el intelecto activo o intelecto agente. Avicena explica que la adquisición de inteligibles depende de la capacidad que cada persona tenga para obtener el término medio de un silogismo ${ }^{50} \mathrm{y}$, por tanto, si bien algunas personas requieren mucha instrucción y se tienen que esforzar para obtener los inteligibles otros, en verdad privilegiados, pue-

sólo menciona que el intelecto in habitu o intelecto disposicional capta los inteligibles secundarios (definiciones, géneros, especies, diferencias, etc.), pero sin usarlos aún (véase Avicena, Šifă': al-Nafs 1.5, pp. 49-50). Finalmente, Avicena explica que tanto los inteligibles primarios como los secundarios son necesarios para la actualización de los inteligibles, misma que tiene lugar en lo que Avicena denomina 'intelecto adquirido' ( 'aql mustafād) (Šifă': al-Nafs 1.5, p. 50).

${ }^{46}$ Véase Avicena, Šifá': al-Nafs 5.5, p. 235.

${ }^{47}$ Véase Avicena, Šifā': al-Nafs 5.5, pp. 234-235.

${ }^{48}$ Véase Avicena, Šifa': al-Nafs 5.5, p. 235.

${ }^{49}$ Véase Avicena, Šifă': al-Nafs 1.5, p. 45.

${ }^{50}$ Avicena, Šifă': al-Nafs 5.6, p. 249. 
den adquirirlos directamente gracias a su poderosa disposición o aptitud natural llamada "intuición" (hads).$^{51}$ En algunos casos, según Avicena, esta intuición puede ser muy robusta, al grado de no requerirse ningún esfuerzo o instrucción para lograr la conjunción con el intelecto activo o intelecto agente, y estos individuos privilegiados son capaces de obtener los inteligibles de forma inmediata. Cuando este tipo de conocimiento tiene lugar, el intelecto material recibe el nombre de "facultad sagrada" (quwā qudsìya):

La obtención del conocimiento, ya sea con ayuda de otro o por sí mismo, es distinta en grado. Hay para quienes es más sencillo conocer [por el proceso de] conceptualización, ya que en ellos esta disposición es más poderosa. De ser éste el caso [en el caso de quien es capaz de obtener el conocimiento] por sí mismo, esta poderosa disposición recibe el nombre de "intuición" (hads). Hay algunos en quienes esta disposición puede ser tan intensa que no necesitan ni mucho esfuerzo, ni entrenamiento o instrucción para [alcanzar la] conjunción con el intelecto activo. [En este caso] la disposición para [alcanzar la conjunción] puede ser tan intensa, que es casi como si realmente poseyeran la segunda disposición-de hecho, es como si conocieran todo por sí mismo. Éste es el grado más alto de esta disposición. En este estado el intelecto material ha de llamarse "facultad sagrada" y, a pesar de formar parte del género del intelecto disposicional, es tan noble que no es algo común a todos. Puede darse el caso de que algunas de estas acciones, que son atribuidas al espíritu sagrado dada su naturaleza poderosa y abrumadora, inunden la imaginación, misma que luego reproduce imitaciones de éstas que pueden ser percibidas por los sentidos y escuchadas como voz, de la manera previamente indicada. $^{52}$

Aunque como se ve Avicena indica que este intelecto es parte del género del intelecto disposicional, subraya sin embargo que éste no es común a todos los seres humanos, y describe sus operaciones de una forma peculiar: en este tipo de acto cognitivo, la imaginación queda desbordada y reproduce las imitaciones de las imágenes recibidas a través de visiones y discursos. Esta descripción corresponde a los eventos proféticos. Un profeta, por tanto, sería un individuo cuya alma recibe instantáneamente la impresión de los inteligibles gracias al intelecto activo o intelecto agente; en palabras de Avicena, el profeta obtiene los principios de todas las cuestiones, el término medio de todo silogismo

${ }^{51}$ Avicena, Šifă': al-Nafs 5.6, p. 248. Para una explicación detallada de la noción que Avicena tiene de hads, véase Gutas, Avicenna and the Aristotelian Tradition: Introduction to Reading Avicenna's Philosophical Works, pp. 179-201.

${ }^{52}$ Avicena, Šifá': al-Nafs 5.6, p. 248. 
y las causas en el mundo. Por esta razón que Avicena afirma que el intelecto sagrado es la más noble entre las facultades humanas y que se trata de un tipo de capacidad profética. ${ }^{53}$ Esta explicación psicológica de la profecía describe este fenómeno como algo natural que, si bien ocurre de manera extraordinaria, se explica por la conjunción que acontece entre la imaginación humana (en el caso de la profecía imaginativa) o el intelecto sagrado (en el caso de la profecía intelectual) y el intelecto activo o intelecto agente:

(...) Puede darse que la intuición le acontezca a una persona por sí misma y que pueda construir el silogismo en su mente sin necesidad de maestro. Esto es algo que varía en cantidad y calidad: en cantidad, porque algunas personas tienen más intuiciones sobre los términos medios; en calidad, porque algunas personas intuyen más rápidamente. Ahora bien, esta variación no está restringida a un nivel particular sino, más bien, siempre es susceptible de incrementar o disminuir. El extremo más bajo es el de alguien que no tiene ningún tipo de intuición, mientras que el extremo más alto es el de alguien que posee intuición sobre todos o la mayoría de los objetos de la investigación científica y que, a su vez, es el más rápido en intuir en la menor cantidad de tiempo. Por lo tanto, es posible que haya un individuo cuya alma esté fortalecida con un nivel de pureza tal y con una conjunción tal con los principios intelectuales, que resplandezca en intuición. Quiero decir [que resplandece en intuición] al recibir [los principios] de todas las cosas por parte del intelecto activo, donde las formas que están en el intelecto activo quedan marcadas en su alma ya sea instantáneamente o casi instantáneamente. Esto no ocurre aceptándolas ciegamente sino, más bien, siguiendo un orden que contiene los términos medios; pues la aceptación ciega de creencias sobre las cosas que son realmente conocibles sólo a través de sus causas no constituye certeza intelectual. Éste es un tipo de condición profética - de hecho, es la facultad más alta de la condición profética - y resulta más apropiado llamar a esta facultad una facultad "sagrada", dado que se trata del nivel más alto de las facultades humanas. ${ }^{54}$

Ahora bien, en Ilāhiyāt 10, Avicena describe a los profetas en los mismos términos en que lo hace en el De anima, como personas con facultades psicológicas especiales, capaces de acceder a la impresión no sólo de los inteligibles, sino también de la moral y de las virtudes prácticas. Avicena menciona que ya ha mostrado el modo en que esto ocurre, sin duda refiriéndose a la explicación psicológica contenida en fi al-Nafs 4.2. Sin embargo, en Ilāhiyāt añade algunos detalles cosmológicos: todo cuanto ocurre en el mundo sublunar emana de los principios celestes; en otras palabras, el mundo terrenal es consecuencia de

${ }^{53}$ Véase Avicena, Šifā': al-Nafs 5.5, pp. 248-249.

${ }^{54}$ Avicena, Šifă': al-Nafs 5.6, pp. 249-250. 
un eterno flujo de emanaciones que comienzan con el Primero o Dios, continúa a través de los poderes activos o inteligencias celestes, y culmina con el intelecto activo o intelecto agente, mismo que funge como causa próxima de todo acontecimiento. Ahora bien, en el caso de la profecía, cuando el intelecto activo se conjuga con las extraordinarias capacidades del profeta, éste logra acceder al mensaje angélico o divino, es decir, a la serie de principios teóricos y prácticos que le permiten gobernar y ser superior a otros hombres:

El más digno entre todos los hombres es aquel cuya alma alcanza la perfección al volverse un intelecto en acto y alcanza las costumbres que constituyen las virtudes prácticas. El más digno entre los hombres será aquel capaz de recibir la profecía, es decir, quien, entre sus facultades del alma, cuente con las tres propiedades distintivas que antes mencioné, es decir, la facultad para escuchar las palabras de Dios, exaltado sea, [la facultad] para ver los ángeles que se le manifiestan a través de una imagen visible. Hemos mostrado la manera en que esto ocurre [en fì alNafs 4.2]. Hemos mostrado que los ángeles toman forma visible para la persona que recibe la revelación y que [el más digno entre los hombres] es capaz de escuchar las voces [provenientes de Dios y sus ángeles]. Por lo tanto, éste las escucha sin que sean voces de personas o de algún animal terrenal. Éste es aquel al quien la revelación es dada..$^{55}$

Nótese cómo, a pesar del lenguaje religioso, este tipo de explicación de la profecía no apela a algún tipo de gracia sobrenatural para explicar la profecía, sino que más bien la describe como un proceso natural en el que a través de la actualización del intelecto, las aquí denominadas "potencias psicológicas" reciben un mensaje divino.

\section{Observaciones finales}

En conclusión, hay diversos aspectos a resaltar en la postura que Avicena guarda ante la profecía dentro del conjunto de obras aquí revisadas. En la Risāla al-Manāmiyya Dios es concebido como la causa última de las visiones en el sueño o aquellas representaciones que proveen conocimiento sobre los eventos futuros a un intelecto particular; sin embargo, Él no es su transmisor directo: la adivinación o profecía ocurre a través de la intervención de un intelecto activo universal que existe afuera o de manera separada de la mente humana. En fi al-Nafs

${ }^{55}$ Avicena, Šifă': Ilāhiyāt 10.1, p. 359.

Al-Qantara XXXVIII 1, 2017, pp. 45-70 ISSN 0211-3589 doi: 10.3989/alqantara.2017.002 
el papel del intelecto activo o intelecto universal se desarrolla en profundidad: este intelecto no sólo es el mediador en el proceso de abstracción, sino también es el proveedor directo de los inteligibles en el caso de los profetas, es decir, aquellas personas privilegiadas que gozan de una disposición o aptitud natural para recibir los principios sobre toda cuestión, y que son capaces de reproducirlas a modo de imágenes usando su facultad imaginativa. El intelecto activo universal es el proveedor tanto en la profecía imaginativa como en la profecía intelectual. Finalmente, en Ilāhiyāt Avicena explica en detalle el proceso emanacionista a través del cual los cuerpos celestes intervienen. La teoría de la profecía en Avicena en todas estas obras parte del modo peculiar en que entiende el proceso intelectivo así como su modelo cosmológico emanacionista. Avicena se basa en presupuestos filosóficos de la tradición antigua para explicar un fenómeno que usualmente es visto como algo sobrenatural o milagroso.

\section{Fuentes}

Al-Fārābī, On the Perfect State (Mabādi' ārā'ahl-al-Madīna al-Fāẹila), Richard Walzer (trad.), Oxford, Clarendon Press, 1985.

Alejandro de Afrodisia, On the Cosmos, Charles Genequand (ed. y trad.), Leiden/Boston, Brill, 2001.

Anónimo, Liber de causis, Rolf Schönberger (trad.), Hamburgo, Felix Meiner Verlag, 2003.

Aristóteles, Acerca del alma, Tomás Calvo Martínez (trad.), Madrid, Gredos, 1983.

Aristóteles, “Acerca de la adivinación” (De Divinatione), en Tratados breves de historia natural, Ernesto la Croce y Alberto Bernabé (trads.), Madrid, Gredos, 1987.

Aristóteles, On the Soul, W. S. Hett (trad.), Cambridge, Harvard University Press, Londres, 2000, Loeb Classical Library (Aristotle VIII).

Aristóteles, "On Prophecy in Sleep" (De Divinatione), en Parva Naturalia, W. S. Hett (trad.), Cambridge, Harvard University Press, Londres, 2000, Loeb Classical Library (Aristotle VIII).

Avicena, "Kitabu ta'bir-ir-ruya of Abu 'Ali b. Sina", M. A. Mu'id Khan (trad.), Indo-Iranica 9/3 (1956), pp. 15-30 y 9/4 (1956), pp. 43-57.

Avicena, "A unique Treatise on the Interpretation of Dreams [Risāla al-Manāmiyya]", M. A. Mu'id Khan (ed.), en Avicenna Commemoration Volume, Calcuta, Iran Society, 1975. 
Avicena, Šifä': al-Nafs, Avicenna's De anima, Being the Psychological Part of Kitāb al-Šifā', Fazlur Rahman (ed.), Londres, Oxford University Press, 1959. Avicena, Shifā': Ilāhiyāt, The Metaphysics of the Healing (A Parallel EnglishArabic Text), Michael Marmura (trad.), Provo, Brigham Young University Press, 2005.

Avempace (Ibn Bāŷŷa), El régimen del solitario, Joaquín Lomba (trad.), Madrid, Trotta, 1997.

Averroes, Epitome a los Parva Naturalia (Talkhīs Kitāb al-Hiss wa-al-maḥsūs) [Librorum Aristotelis qui Parva Naturalia Vocantur (Textum Arabicum)], Harry Blumberg (ed.), Cambridge Mass.: The Mediaeval Academy of America, 1972, Corpus commentariorum Averrois in Aristotelem. Versionum arabicorum, vol. VII, A. Wolfson, S. Pines and Z. Stewart (eds.).

Galen, The Alexandrian Epitomes of Galen (A Parallel English-Arabic Text), John Walbridge (trad.), Provo, Brigham Young University Press, 2014.

Maimónides, Guía de los perplejos, David Gonzalo Maeso (ed. y trad.), Madrid, Trotta, 2005.

Plotino, Enéadas V-VI, Jesús Igal (trad.), Madrid, Gredos, 1998.

Proclo, Elements of Theology, E. R., Dodds (ed. y trad.), Oxford University, Oxford, 1963.

\section{Bibliografía}

Black, Deborah, "Estimation in Avicenna: The Logical and Psychological Dimensions", Dialogue, 32 (1993), pp. 219-258.

Black, Deborah, "Imagination and Estimation: Arabic Paradigms and Western Transformations", Topoi, 19/1 (2000), pp. 59-75.

D’Ancona, Cristina, "La notion de «cause» dans les textes Néoplatoniciens Arabes", en C. Chiesa y L. Freuler (eds.), Métaphysiques Médiévales. Études en l'honneur d'André de Muralt, Genève-Lausanne-Neuchâtel, Cahiers de la Revue de Théologie et de Philosophie, 1999, pp. 47-68.

D'Ancona, Cristina, L'influence du vocabulaire arabe: "Causa Prima est esse tantum", en J. Hamesse y C. Steel (eds.), L'élaboration $d u$ vocabulaire philosophique au Moyen Age. Actes du Colloque International de Louvain laNeuve et Leuven, 12-14 septiembre 1998, Turnhout, Brepols, 2000, pp. 51-97.

D’Ancona, Cristina, “"Causa prima superior est omni narratione». Il tema delle sifat Allah nel primo neoplatonismo arabo", Oriente moderno, 19 (2000), pp. 519-555.

Daiber, Hans, "Salient Trends of the Arabic Aristotle", en G. Endress y R. Kruk (eds.), The Ancient Tradition in Christian and Islamic Hellenism: Studies on the Transmission of Greek Philosophy and Science, Leiden, Brill, 1997, pp. 29-41. 
Davidson, Herbert, Alfarabi, Avicenna, and Averroes, on Intellect, New YorkOxford, Oxford University Press, 1992.

Di Martino, Carla, "La Perception Spirituelle. Perspectives de Recherche pour l'Historie des Parva Naturalia dans la Tradition Arabo-Latine", Veritas, 52/3 (2007), pp. 21-35.

Di Martino, Carla, "Memory and Recollection in Ibn Sīnā's and Ibn Rushd's Philosophical Texts Translated into Latin in the Twelfth and Thirteenth Centuries: A Perspective on the Doctrine of the Internal Senses in Arabic Psychological Science", en H. Lagerlund (ed.), Forming the Mind. Essays on the Internal Senses and the Mind/Body Problem from Avicenna to the Medical Enlightenment, Dordrecht, Springer, 2007, pp. 17-25.

Gutas, Dimitri, Avicenna and the Aristotelian Tradition: Introduction to Reading Avicenna's Philosophical Works, Leiden, Brill, 2014.

Gutas, Dimitri, "Imagination and Transcendental Knowledge in Avicenna", en J. Montgomery (ed.), Arabic Theology, Arabic Philosophy: From the Many to the One. Essays in Celebration of Richard M. Frank, Leuven, Peeters, 2006, pp. 337-354.

Hansberger, Rotraud, The Transmission of Aristotle's Parva Naturalia in Arabic, Somerville College, University of Oxford, Faculty of Oriental Studies, 2006.

Hansberger, Rotraud, "How Aristotle Came to Believe in God-given Dreams: The Arabic Version of De divinatione per somnum", en L. Marlow (ed.), Dreaming Across Boundaries: The Interpretation of Dreams in Islamic Lands, Washington-Cambridge, Ilex Foundation / Center for Hellenic Studies, 2008, pp. 50-77.

Hansberger, Rotraud, “Kitāb al-Hiss wa-l-mahsūus: Aristotle’s Parva Naturalia in Arabic Guise", en C. Grellard y P.-M. Morel (eds.), Les Parva naturalia d'Aristote: Fortune antique et médiévale, Paris, Publications de la Sorbonne, 2010, pp. 143-162.

Hansberger, Rotraud, "Plotinus Arabus Rides Again", Arabic Sciences and Philosophy, 21 (2011), pp. 57-84.

Hansberger, Rotraud, "The Arabic Adaptation of the Parva Naturalia (Kitāb alHiss wa-l-mahsūs)", Studia graeco-arabica, 4 (2014), pp. 301-314.

Hasse, Dag Nikolaus, Avicenna's De anima in the Latin West, Londres, The Warburg Institute, 2000.

López-Farjeat, Luis Xavier, “Avicenna and Thomas Aquinas on Natural Prophecy”, American Catholic Philosophical Quarterly, 88/2 (2014), pp. 309-333.

Pines, Shlomo, "The Arabic Recension of Parva Naturalia and the Philosophical Doctrine Concerning Veridical Dreams According to al-Risāla al-Manāmiyya and Other Sources", Israel Oriental Studies, 4 (1974), pp. 104-153.

Smith, C. U. M., "Beginings of Ventricular Psychology", en C. U. M Smith y H. Whitaker (eds.), Brain, Mind and Consciousness in the History of Neuroscience, Springer, Dordrecht, pp. 2-19. 
Steinschneider, Moritz, "Die Parva Naturalia des Aristoteles bei den Arabern", Zeitschrift der Deutschen Morgenlëndischen Gesellschaft, 37 (1883), pp. 477492 y Zeitschrift der Deutschen Morgenlëndischen Gesellschaft, 45 (1891), pp. 447-453.

Taylor, Richard, "Primary Causality and $i b d \bar{a}$ ' (creare) in the Liber de causis", en A. Mensching-Estakhr y M. Städtler (eds.), Wahrheit und Geschichte. Die gebrochene Tradition metaphysischen Denkens. Festschrift zum 70 Geburtstag von Günther Mensching, Würzburg, Königshausen \& Neumann, 2012, pp. $115-136$.

Taylor, Richard, "Primary and Secondary Causality", en Richard C. Taylor \& Luis Xavier López-Farjeat (eds.), The Routledge Companion to Islamic Philosophy, Nueva York \& Londres, Routledge, 2016, pp. 225-235.

Wolfson, Harry A., "The Internal Senses in Latin, Arabic, and Hebrew Philosophic Texts", Harvard Theological Review, 28/2 (1935), pp. 69-133.

Recibido: $16 / 11 / 2015$

Aceptado: 19/09/2016 